\title{
The effect of children on female labor force participation in urban Iran
}

\author{
Ebrahim Azimi
}

Correspondence: eaa20@sfu.ca Department of Economics, Simon Fraser University, 8888 University Drive, Burnaby, British Columbia, Canada

\begin{abstract}
This paper estimates the effect of having children on labor force participation of mothers in urban Iranian areas. I exploit sex composition of children as an exogenous source of variation in family size to account for endogeneity of fertility. Using information from the Iranian Household Income and Expenditure Survey (HIES) over three samples, namely, households with one and more, two and more, and three and more children, I find no significant effect of fertility on female labor force participation in Iran.

JEL codes: J13, J22
\end{abstract}

Keywords: Female labor force participation; Fertility; Children sex composition; Son preference; Instrumental variables

\section{Introduction}

In economic literature, children are often considered a barrier to female labor force participation (FLFP). In the last three decades, fertility in Iran has dropped sharply from an average of seven births per woman in 1984 to less than two births in 2005. Although fertility in Iran has experienced one of the fastest declines in modern human history, no considerable rise in FLFP in Iran is documented (Aghajanian 1995; Abbasi-Shavazi et al. 2009; Majbouri 2010). Using household-level information, this paper investigates the effect of children on FLFP of mothers in urban Iran.

The association between fertility and FLFP is extensively documented in theoretical models of work and family. While it is difficult to empirically estimate the endogenous effect of fertility on FLFP (Schultz 1981; Goldin 1995), several studies estimate its causal effect by exploiting an exogenous variation in family size. For example, Rosenzweig and Wolpin (1980) and Bronars and Grogger (1994) use twinning at the first birth. Angrist and Evans (1998) use an instrumental variables (IV) strategy based on the sex composition of siblings in families with two or more children. Agüero and Marks (2008) exploit random assignment of infertility as an exogenous variation in family size. Using the Iranian Household Income and Expenditure Survey (HIES), this paper contributes new evidence on the effect of fertility on FLFP by using an IV strategy.

I follow Angrist and Evans (1998) strategy to construct IV estimates of the effect of fertility on FLFP based on sex composition of children. While in the US, parents are more likely to have a third child if their first two children are of the same sex, in Iran, as parents prefer sons to daughters, the presence of daughters in their previous 
children acts as a positive shock to fertility. To show this relationship and investigate the effect of children on FLFP, I construct three samples: one with families with one and more children $\left(1^{+}\right)$, another with two and more children $\left(2^{+}\right)$, and the third with three and more children $\left(3^{+}\right)$. In all these samples, families with more daughters than sons are more likely to have another child. In other words, presence of more girls relative to boys results in an increased likelihood of having another child. Considering this relationship, I construct an IV based on the sex composition of previous children to investigate the effect of fertility on FLFP by using dummies for the gender of the first child, the first two children, and the first three children in the samples of $1^{+}, 2^{+}$, and $3^{+}$, respectively. As sex-selective abortion and infanticide are rare in Iran, I consider sex composition among children as essentially random. To support this claim, I follow Almond and Edlund (2008) by observing that sex ratio does not vary significantly with birth order parity and sex composition of the previous children.

To the best of my knowledge, this is the first estimation of the effect of fertility on FLFP in Iran. While most empirical estimations of the effect of fertility on FLFP find a negative impact, which in most cases is less negative than its ordinary least squares (OLS) counterparts, I find no significant effect of children on the labor force participation of Iranian mothers in urban areas. This result is similar to Agüero and Marks (2008), who find an insignificant effect of fertility on FLFP in six Latin American countries.

The rest of this paper is organized as follows. In the next section, I present the data. In section "Sex composition of children and fertility", I describe the methodology and explain how fertility in Iran is influenced by the sex composition of previous children. Section "Estimation results" presents the results, and section "Conclusion" concludes.

\section{Data and descriptive statistics}

I use data from the HIES (1994-2003). This survey is conducted annually by the Statistical Center of Iran. For each member of a family, this survey contains information on demographic characteristics such as geographic location, age, gender, education, relationship with the householder, marriage status, employment status, occupation, and income. It also contains information on family expenditures, housing characteristics, and ownership of assets and amenities.

The number of households in the HIES ranged from 17,500 in 1998 to 36,500 in 1995. To ensure that the insignificant effect of fertility on FLFP is not a result of insufficient data, I use 10 rounds of the HIES data (1994-2003), all of which follow the same definition for labor force participation.

The following restrictions are applied to the sample. 1) Polygamous families are excluded from the sample; otherwise, it would have been impossible to match the children to the women. 2) I exclude all cases wherein two or more families share a common residence. Given that household identification, which is based on residential address, is the only way to distinguish families, I am unable to distinguish children of families that share the same residence. 3) Similar to most household surveys, the HIES does not track children according to their households. To match the children with their respective mothers, I restrict the sample to women aged between 20-35 years whose 
oldest child is younger than 18 years. Few women younger than 19 have two or more children, and women older than 35 are likely to have children who have already migrated from the family. By restricting the sample, I ensure that the family's oldest child is still living with the parents and has not migrated from the family on account of marriage, higher education, or work.

Additional file 1: Table S1 compares the selected sample with the overall sample of women for some measures of fertility and FLFP. The three samples of women include: (1) women aged between 20-35 years; (2) women aged between 36-50 years; and (3) women aged between 20-35 years with two or more children and whose oldest child is younger than 18. I highlight three features of fertility and FLFP in Iran from 1990-2004 in this table. First, we observe a declining trend in the number of children; second, depending on the year of the interview, a low FLFP rate of 10-14 percent in urban areas for the selected sample is observed. The rigidity of FLFP in this period is an important feature that has been addressed in the literature (Majbouri 2010). Third, fertility and FLFP are comparable for all three categories.

Trends in fertility and FLFP are depicted in Figures 1 and 2, respectively, for three subsamples of women from the HIES data.

While fertility shows a sharp decline during this period, based on economic theory, we expect an increase in FLFP. However, we observe no such increase over the period in Figure 2. The objective of this paper is to investigate whether and to what extent fertility impacts FLFP in urban Iran. I continue this discussion in section "Estimation results", where I present the results.

Table 1 reports the summary statistics for each sample of the 20 to 35-year-old mothers in the three samples of $1^{+}, 2^{+}$, and $3^{+}$.

\section{Sex composition of children and fertility}

Similar to Angrist and Evans (1998), I use the following two-stage least squares (2SLS) regression model of FLFP:

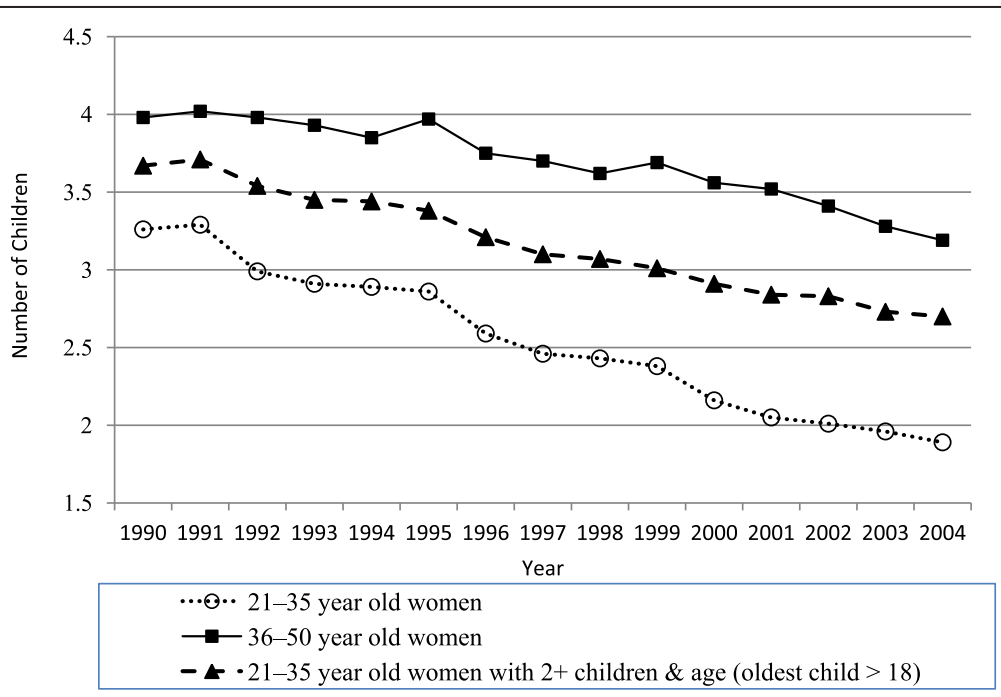

Figure 1 Trend in number of children by age group and family size: 1990-2004. 


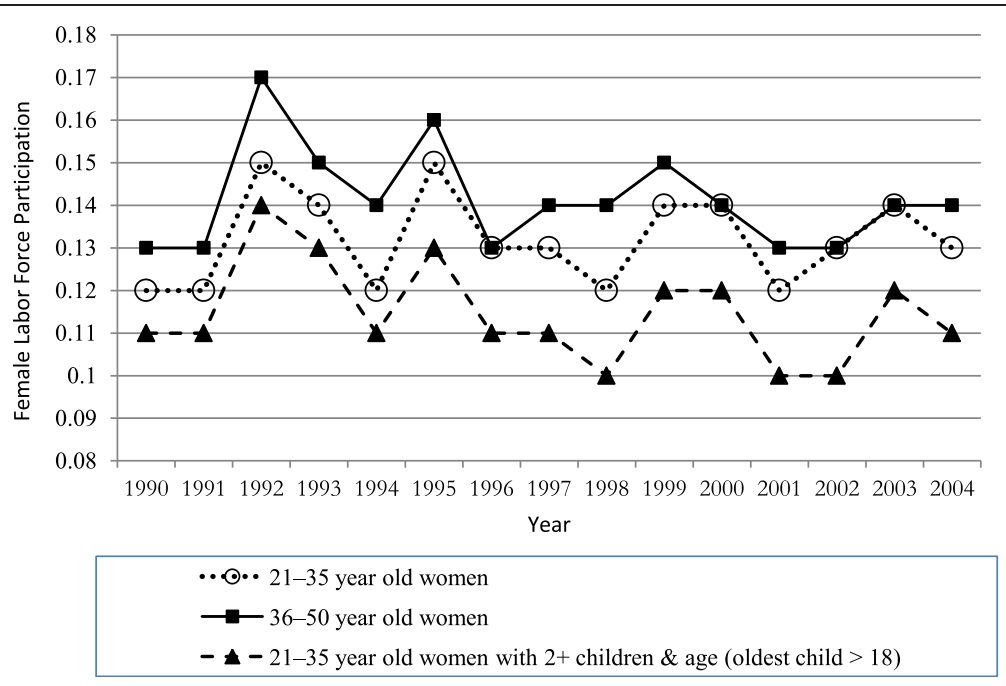

Figure 2 Trend in female labor force participation by age group and family size: 1990-2004.

$$
\begin{aligned}
& x_{i}=\alpha_{0} \cdot w_{i}+\alpha_{1} \cdot z_{i}+\varepsilon_{i} \\
& y_{i}=\beta_{0} \cdot w_{i}+\beta_{1} \cdot \hat{x_{\ell}}+\eta_{i}
\end{aligned}
$$

Here, $x_{i}$ is a measure of fertility for woman $i ; y_{i}$ is an indicator of FLFP; $w_{i}$ includes socioeconomic characteristics of $i$; and $z_{i}$ denotes the instrumental variable based on the sex composition of the children. The instrumental variable is an indicator for the sex composition of the children. The theoretical framework underlying the effect of son preference on fertility is captured by the quality-quantity model of fertility developed

\begin{tabular}{|c|c|c|c|c|c|c|}
\hline & \multicolumn{2}{|c|}{$1^{+}$sample } & \multicolumn{2}{|c|}{$2^{+}$sample } & \multicolumn{2}{|c|}{$3^{+}$sample } \\
\hline & Mean & St. dev. & Mean & St. dev. & Mean & St. dev. \\
\hline FLFP & 0.129 & $(0.335)$ & 0.116 & $(0.320)$ & 0.0978 & $(0.297)$ \\
\hline Number of children & 2.627 & $(1.431)$ & 3.110 & $(1.279)$ & 3.917 & $(1.131)$ \\
\hline Three-and-more-children indicator & 0.447 & $(0.497)$ & 0.579 & $(0.494)$ & 1 & (0) \\
\hline Four-and-more-children indicator & 0.235 & $(0.424)$ & 0.305 & $(0.460)$ & 0.526 & $(0.499)$ \\
\hline Firstborn son indicator & 0.514 & $(0.500)$ & 0.509 & $(0.500)$ & 0.497 & $(0.500)$ \\
\hline Second-born son indicator & 0.510 & $(0.500)$ & 0.510 & $(0.500)$ & 0.502 & $(0.500)$ \\
\hline Two-son indicator & 0.260 & $(0.439)$ & 0.260 & $(0.439)$ & 0.255 & $(0.436)$ \\
\hline Two-daughter indicator & 0.241 & $(0.428)$ & 0.241 & $(0.428)$ & 0.257 & $(0.437)$ \\
\hline Age & 28.88 & $(3.967)$ & 29.69 & $(3.685)$ & 30.53 & $(3.376)$ \\
\hline Age at first birth & 19.98 & $(3.462)$ & 19.25 & $(3.096)$ & 18.49 & $(2.745)$ \\
\hline Years of schooling & 6.715 & $(4.267)$ & 6.023 & $(4.076)$ & 4.810 & $(3.727)$ \\
\hline Presence of relatives in the family & 0.0893 & $(0.285)$ & 0.0896 & $(0.286)$ & 0.0962 & $(0.295)$ \\
\hline Incidence of zero in nonlabor income & 0.812 & $(0.391)$ & 0.809 & $(0.393)$ & 0.807 & $(0.394)$ \\
\hline Logarithm of nonlabor income & 2.581 & $(5.426)$ & 2.616 & $(5.449)$ & 2.622 & $(5.427)$ \\
\hline Observations & 56845 & & 43868 & & 25399 & \\
\hline
\end{tabular}

Table 1 Summary statistics: women aged 21-35 years

Note: I report the mean of each variable with the standard deviation in parentheses.

The variable "age at first birth" is measured by assuming that matching of the women with their respected children is perfect. Therefore, this variable is measured by error. 
by Becker and Lewis (1974). Based on this model, in the current study, parents derive utility from quantity and quality of children. The sex composition of children in this model is viewed as a source of utility related to the quality of children. If parents are not satisfied with the sex composition of children, they will be more likely to expand their family to draw utility from quantity of children or from a more desired composition of children. Therefore, having more children is a response to dissatisfaction from the sex composition of the children.

Based on the above framework and similar to Ben-Porath and Welch (1976), I analyze the effect of the sex composition of children on fertility among Iranian families. Table 2 reports how the firstborn's sex influences the number of children. In the $1^{+}$sample, the difference by the first child's sex suggests that families with a firstborn daughter are one percentage point more likely to have a second child. This is consistent with the preference for a son among Iranian parents. Similarly, in the $2^{+}$and $3^{+}$samples, the presence of a firstborn son reduces the likelihood of a third and a fourth child. Thus, the firstborn's sex is a plausible instrumental variable for number of children.

Similarly, among families with two or more children, the difference by the firstborn's sex suggests that those with a firstborn daughter are 2.4 percentage points more likely to have a third child (Table 3). This finding is also consistent with the fact that Iranian parents have a marked son preference, especially for the first birth.

Similar to the case of the firstborn daughter, the second daughter also increases the likelihood of having a third child. The effect, however, is smaller than that of the firstborn girl. Parents of a second daughter are 1.7 percentage points more likely to have a third child. Further, while parents with two sons are 1.2 percentage points less likely to have a third child, parents with two girls are 4.5 percentage points more likely to have a third child. This also shows that parents of a mix of male and female children are 2.4 percentage points less likely to have a third child relative to parents of same-sex children.

There are three points worth mentioning about Table 3. First, all the evidence demonstrates a marked preference for sons among Iranian families; while sons reduce the likelihood of a third child, daughters increase it. Second, the effect of two daughters is larger compared to other combinations. Third, this table shows that the sex composition of children has a strong explanatory power on fertility

Table 2 Fraction of families who had a second child depending on the sex of the first child

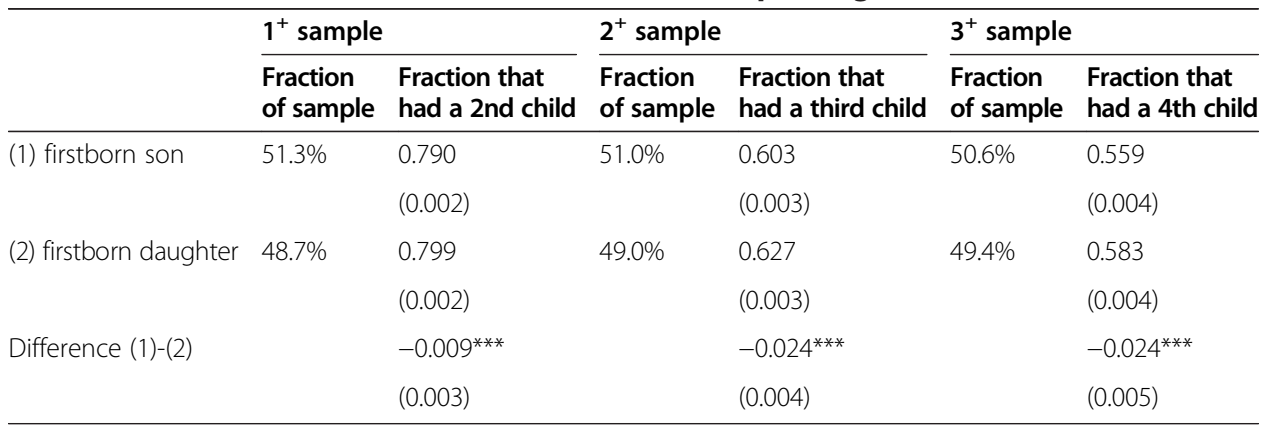

Note: Standard errors are reported in parentheses.

*** significant at the $1 \%$ level. 
Table 3 Fraction of families who had another child depending on the sex composition of previous children: $\mathbf{2}^{+}$sample

\begin{tabular}{lll}
\hline & Fraction of sample & Fraction that had a third child \\
\hline (1) firstborn son & $51.0 \%$ & $0.603(0.003)$ \\
(2) firstborn daughter & $49.0 \%$ & $0.627(0.003)$ \\
Difference: (1)-(2) & & $-0.024^{* * *}(0.004)$ \\
(1) second-born son & $51.1 \%$ & $0.607(0.003)$ \\
(2) second-born daughter & $48.9 \%$ & $0.624(0.003)$ \\
Difference: (1)-(2) & & $-0.017^{* * *}(0.004)$ \\
(1) two sons & $26.2 \%$ & $0.607(0.004)$ \\
(2) not (two sons) & $73.8 \%$ & $0.618(0.002)$ \\
Difference: (1)-(2) & & $-0.012^{* * *}(0.005)$ \\
(1) two daughters & $24.0 \%$ & $0.649(0.004)$ \\
(2) not (two daughters) & $76.0 \%$ & $0.604(0.002)$ \\
Difference: (1)-(2) & & $0.045^{* * *}(0.005)$ \\
(1) mixed sex & $50.2 \%$ & $0.627(0.003)$ \\
(2) same sex & $49.8 \%$ & $0.603(0.003)$ \\
Difference: (1)-(2) & & $0.024^{* * *}(0.004)$ \\
\hline
\end{tabular}

Note: Standard errors are reported in parentheses. ***significant at the $1 \%$ level.

decisions in Iranian families. Based on these results, I use an indicator of two daughters as an instrumental variable to estimate the effect of a third child on FLFP in the $2^{+}$sample.

Similarly, Table 4 reports the relation between sex composition of children and probability of having a fourth child in families with at least three children. Based on this table, I use the indicator of having at least two sons as an instrument to investigate the effect of a fourth child on FLFP in the $3^{+}$sample.

Random assignment of sex composition makes it very likely that these IV estimates of the effect of fertility on FLFP have a causal interpretation. Selective abortion and infanticide are quite rare in Iran because both have been illegal since the 1979 Islamic Revolution, except in very specific cases where the mother is in serious danger or the baby is expected to born with a severe disease (Hoodfar 1996; Mehryar et al. 2007). Thus, we treat the gender composition of children as essentially random.

One empirical test for random assignment of the sex composition of children is to compare the sex ratio by birth order and sex of previous children (Almond and Edlund 2008). For the general human population, sex ratio, defined as the proportion of males to females, is about 1.05 , with the exception of during and after wartime, where it was documented to be slightly higher. Otherwise, a higher-than-normal sex ratio is a sign of sex-selective abortion. In such cases, the sex ratio will depend on previous children's sex composition. For example, due to the availability of prenatal sex determination, a two-child family that already has a daughter and prefers sons is more likely to abort a girl fetus relative to a boy fetus. Table 5 reports sex ratio by birth order and previous children's sex composition. No significant inflated sex ratio is evident from this table. Although the sex ratio is slightly larger than 1.05 for the third child, there is no significant difference between the sex ratios of families with two sons and families with two daughters. Thus, the sex composition of children can be treated as random. 
Table 4 Fraction of families who had a fourth child depending on parity and sex composition of previous children

\begin{tabular}{|c|c|c|}
\hline & Fraction of sample & Fraction that had a 4th child \\
\hline \multirow[t]{2}{*}{ (1) 3 sons } & $13.6 \%$ & 0.560 \\
\hline & & $(0.007)$ \\
\hline \multirow[t]{2}{*}{ (2) other combinations } & $86.4 \%$ & 0.573 \\
\hline & & $(0.003)$ \\
\hline \multirow[t]{2}{*}{ Difference: (1)-(2) } & & $-0.013^{* *}$ \\
\hline & & $(0.007)$ \\
\hline \multirow[t]{2}{*}{ (1) 3 daughters } & $12.7 \%$ & 0.557 \\
\hline & & $(0.007)$ \\
\hline \multirow[t]{2}{*}{ (2) other mixes } & $87.3 \%$ & 0.573 \\
\hline & & $(0.003)$ \\
\hline \multirow[t]{2}{*}{ Difference: (1)-(2) } & & $-0.015^{* *}$ \\
\hline & & $(0.008)$ \\
\hline \multirow[t]{2}{*}{ (1) same sex } & $25.8 \%$ & 0.594 \\
\hline & & $(0.005)$ \\
\hline \multirow[t]{2}{*}{ (2) mixed sex } & $74.2 \%$ & 0.563 \\
\hline & & $(0.003)$ \\
\hline \multirow[t]{2}{*}{ Difference: (1)-(2) } & & $0.031^{* * *}$ \\
\hline & & $(0.006)$ \\
\hline \multirow[t]{2}{*}{ (1) 2 sons, 1 daughter } & $38.0 \%$ & 0.548 \\
\hline & & $(0.004)$ \\
\hline \multirow[t]{2}{*}{ (2) other compositions } & $62.0 \%$ & 0.585 \\
\hline & & $(0.003)$ \\
\hline \multirow[t]{2}{*}{ Difference: (1)-(2) } & & $-0.036^{* * *}$ \\
\hline & & $(0.005)$ \\
\hline \multirow[t]{2}{*}{ (1) 1 son, 2 daughters } & $36.2 \%$ & 0.578 \\
\hline & & $(0.004)$ \\
\hline \multirow[t]{2}{*}{ (2) other compositions } & $63.8 \%$ & 0.567 \\
\hline & & $(0.003)$ \\
\hline \multirow[t]{2}{*}{ Difference: (1)-(2) } & & $0.011^{* *}$ \\
\hline & & $(0.005)$ \\
\hline
\end{tabular}

Note: Standard errors are reported in parentheses.

${ }^{* * *}$ significant at the $1 \%$ level, ${ }^{* *}$ significant at the $5 \%$ level.

Table 5 Sex ratio by parity and sex composition of previous children

\begin{tabular}{llllll}
\hline Birth order & Previous children & Observations & Sex ratio & \multicolumn{2}{c}{$\mathbf{9 5 \% \text { confidence interval }}$} \\
\cline { 5 - 6 } & & & 1.055 & Lower bound & Upper bound \\
\hline First & & 132,599 & 1.044 & 1.066 \\
Second & girl & 51,689 & 1.032 & 1.015 & 1.050 \\
& boy & 53,920 & 1.049 & 1.031 & 1.066 \\
\multirow{3}{*}{ Third } & girl, girl & 17,356 & 1.082 & 1.051 & 1.115 \\
& girl, boy & 33,703 & 1.067 & 1.044 & 1.090 \\
& boy, boy & 17,685 & 1.080 & 1.048 & 1.112 \\
\hline
\end{tabular}


The results of the 1996 and 2006 Iranian Censuses in Additional file 1: Table S2 support the randomness of sex composition in Iran.

An alternative test for random assignment of child sex composition is to compare demographic characteristics of families by the sex composition of children (Angrist and Evans 1998). If sex composition is random, there is no significant difference between demographic characteristics of families by this composition, as the insignificant differences in Table 6 suggest.

The random assignment of sex composition of children makes it very likely that the reduced form regressions of fertility and FLFP have a causal interpretation. Section "Estimation results" reports this estimation, and the results confirm that the three dummies of firstborn son, two daughters, and two sons and more are plausible instrumental variables for investigating the effect of fertility on FLFP in the $1^{+}, 2^{+}$, and $3^{+}$samples, respectively. I use number of children and indicators of having more than two and three children as the measures of fertility for the $1^{+}, 2^{+}$, and $3^{+}$samples, respectively.

\section{Estimation results}

In this section, I estimate the effect of having more children on FLFP using the 2SLS regression model of FLFP shown in equations (1) and (2). As explained earlier, I estimate the model for three subsamples of women. I use number of children, an indicator denoting that a woman has more than 2 children, and an indicator denoting that a woman has more than three children as measures of fertility for the samples $1^{+}, 2^{+}$, and $3^{+}$, respectively. The respective instrumental variables are indicators of a firstborn son, two daughters, and two or more sons.

All the specifications include indicators of age, namely, I( $25 \leq$ age $\leq 29)$, I( $30 \leq$ age $\leq 35)$; indicators of schooling, namely, I $(1 \leq$ schooling $\leq 5)$, I $(6 \leq$ schooling $\leq 8), \mathrm{I}(9 \leq$ schooling $\leq 12)$, I $\left(13 \leq\right.$ schooling); age at first birth ${ }^{1}$; log(nonlabor income); and year effects.

Table 7 reports the results of the OLS and IV estimates of the effect of children on FLFP for all three samples as well as the results of the first-stage estimates.

All three samples confirm the strong association between fertility and child sex composition. The $F$-statistics of a test for weak instrument hypothesis based on Stock and Yogo (2005) strongly rejects the null hypothesis of a weak instrument. The IV estimates suggest no significant effect of fertility on FLFP, while the OLS estimates report negative effects. Although the OLS estimates are small, they are significant. Most studies of

Table 6 Difference in mean for demographics by sex composition of children

\begin{tabular}{llll}
\hline & A firstborn son & Two daughters & Two or more sons \\
\hline Age & -0.012 & 0.030 & -0.020 \\
Literacy & $(0.026)$ & $(0.034)$ & $(0.036)$ \\
& -0.002 & -0.004 & 0.006 \\
Education & $(0.003)$ & $(0.005)$ & $(0.006)$ \\
& -0.013 & -0.050 & 0.051 \\
Husband's years of education & $(0.035)$ & $(0.044)$ & $(0.044)$ \\
& -0.004 & -0.042 & 0.081 \\
Sample & $(0.038)$ & $(0.049)$ & $(0.053)$ \\
\hline
\end{tabular}

Note: Standard errors are reported in parentheses. 
Table 7 OLS and 2SLS estimates of the effect of fertility on FLFP in urban Iran

\begin{tabular}{|c|c|c|c|c|c|c|}
\hline & \multicolumn{2}{|l|}{$1^{+}$sample } & \multicolumn{2}{|l|}{$2^{+}$sample } & \multicolumn{2}{|c|}{$3^{+}$sample } \\
\hline & OLS & 2SLS & OLS & $2 S L S$ & OLS & $2 S L S$ \\
\hline \multicolumn{7}{|c|}{ First-stage results: fertility equation } \\
\hline \multirow[t]{2}{*}{ A firstborn son } & & $-0.106^{* * *}$ & & & & \\
\hline & & $(0.009)$ & & & & \\
\hline \multirow[t]{2}{*}{ Two daughters } & & & & $0.042^{* * *}$ & & \\
\hline & & & & $(0.004)$ & & \\
\hline \multirow[t]{2}{*}{ Two or more sons } & & & & & & $-0.044^{* * *}$ \\
\hline & & & & & & $(0.005)$ \\
\hline \multicolumn{7}{|c|}{ Estimation results: FLFP equation } \\
\hline \multirow[t]{2}{*}{ Number of children } & $-0.008^{* * *}$ & 0.005 & & & & \\
\hline & $(0.001)$ & $(0.026)$ & & & & \\
\hline \multirow[t]{2}{*}{ More than 2 children } & & & $-0.011^{* * *}$ & -0.033 & & \\
\hline & & & $(0.004)$ & $(0.060)$ & & \\
\hline \multirow[t]{2}{*}{ More than 3 children } & & & & & $-0.009^{* *}$ & -0.019 \\
\hline & & & & & $(0.004)$ & $(0.068)$ \\
\hline Observations & 56,845 & 56,845 & 43,868 & 43,868 & 25,399 & 25,399 \\
\hline 1st stage $R$-squared & & 0.562 & & 0.344 & & 0.226 \\
\hline 2nd stage $R$-squared & 0.183 & 0.183 & 0.152 & 0.151 & 0.084 & 0.083 \\
\hline IV F-statistics & & 149.253 & & 149.430 & & 89.917 \\
\hline
\end{tabular}

Note: All the specifications include indicators of age: I( $25 \leq$ age $\leq 29), \mathrm{I}(30 \leq$ age $\leq 35)$; indicators of schooling: I( $1 \leq \mathrm{schooling} \leq 5)$, $\mathrm{I}(6 \leq$ schooling $\leq 8)$, I(9 $\leq$ schooling $\leq 12)$, I(schooling $\leq 13)$; age at first birth; log(nonlabor income); and year effects. Standard errors are reported in parentheses. ${ }^{* * *}$ significant at the $1 \%$ level, ${ }^{* *}$ significant at the $5 \%$ level.

the causal effect of fertility on FLFP find a negative effect, which is usually smaller than the OLS estimates but is still significant. For example, using the firstborn's sex as an instrumental variable; Chun and Oh (2002) find that an additional child reduces the labor force participation of Korean mothers by 27\%. Angrist and Evans (1998) estimate the effect of a third child on women's income to be -0.12 . On the other hand, Agüero and Marks (2008) find no evidence that fertility has a causal effect on FLFP.

Although the insignificant effect of fertility on FLFP is consistent with the aggregate trend of FLFP for urban Iranian families (see Figures 1 and 2), the result is nevertheless surprising.

My finding suggests that children at the extensive margin are not a barrier for the female labor supply. However, one possibility is that fertility influences labor supply of women at the intensive margin. That is, women may change their work hours in response to having a larger family. Unfortunately, information on hours of work are not available in the HIES. Therefore, it is not feasible to estimate the effect of children on female labor supply at the intensive margin. Even if this is a plausible explanation, the rigidity of FLFP at low levels is still surprising.

The low rate of FLFP in Iran and its rigidity over the last three decades have been referred to as a puzzle in development literature (Majbouri 2010). It is more surprising to know that this rigidity was concurrent with a sharp decline in fertility, as mentioned earlier, and a considerable increase in the education of women. For example, according to the Statistical Center of Iran, the female-to-male student ratio in Iranian public and private colleges has increased from less than 0.4 in 1990 to about 1.2 in 2005. 
With the sharp decline in fertility and considerable increase in women's education in Iran, we expect an increase in FLFP. However, FLFP has remained low at 10-14 percent. While investigating the reasons behind the low rate and rigidity of FLFP is outside the scope of this paper, I state a few potential reasons: Many observers believe that religion is the main reason for the low representation of women in the labor market (Sharabi 1988). They emphasize the common problem of low FLFP throughout the Middle East and attribute it to the influence of traditional and religious norms. The suggested mechanism is that traditional norms result in discrimination against women in the labor market, by restricting both labor supply and labor demand for women. This explanation, however, does not seem plausible as countries like Bangladesh and Indonesia are predominantly Muslim but have high rates of FLFP.

Using cross-country data, Ross (2008) shows that the effect of Islam disappears as he controls for oil and gas income, and he concludes that oil, not Islam, is responsible for low rates of FLFP in Iran and other Middle Eastern countries. Majbouri (2015) challenges this argument by proposing a mechanism through which oil and gas income along with traditional institutions account for the rigidity of FLFP. He explains that oil and gas income acts as rent and strengthens traditional norms and the religion's influence among Muslim countries with access to oil income.

\section{Conclusion}

Rigidity of FLFP in urban Iran in the last three decades has been a consensus in development literature. It is more surprising to know that it has been simultaneous with the period in which fertility has sharply declined and women's education has considerably increased (Majbouri 2010). I investigate the causal effect of fertility on FLFP to shed light on a part of this puzzle.

Following Angrist and Evans (1998), I exploit the random assignment of sex composition of children as an instrument to investigate the causal effect of fertility on FLFP among Iranian families in urban areas. As Iranian parents prefer to have sons relative to daughters, I show that the presence of sons reduces the likelihood of having more children in Iranian families. Based on this information, I exploit the sex composition of children to investigate the effect of fertility on FLFP.

While most estimates of the causal effect of fertility on FLFP report negative effects, I find no evidence that the presence of more children is a barrier for mothers to work. This finding is similar to that of Agüero and Marks (2008) and consistent with the aggregate trend in FLFP in urban Iran. Oil and gas income along with traditional institutions in Iran are considered to account for the rigidity of FLFP (Majbouri 2015).

\section{Endnote}

${ }^{1}$ As explained in section "Data and descriptive statistics", I restrict the sample according to the ages of the women and their oldest child to match the women with their respective children. If the match is not close to perfect, the estimate of the variable "age at first birth" will be erroneous, resulting in a bias in estimates. In my result, however, excluding this variable does not change the main finding of the paper; that is, fertility continues to have an insignificant effect on FLFP. 


\section{Additional file}

Additional file 1: Table S1. Fertility and FLFP in Iran during 1990-2004. Table S2. Under-18 population by gender and sex ratio in Iran.

\section{Competing interests}

The IZA Journal of Labor \& Development is committed to the IZA Guiding Principles of Research Integrity. The author declares that he has observed these principles.

\section{Acknowledgements}

The research presented in this paper is part of my PhD dissertation at Simon Fraser University. I thank Simon Woodcock and Krishna Pendakur for their support and advice. I also thank Jane Friesen, Brian Krauth, Andrew McGee, Hitoshi Shigeoka, Fernando Aragon, Chris Muris, Mehdi Majbouri, all the participants of the labor and family session at the Canadian Economic Association conference 2010 at University of Ottawa, and participants at the 2011 HAND forum at Massachusetts Institute of Technology, the editor (David Lam), and the anonymous referee for helpful comments. All remaining mistakes are mine.

Responsible editor: David Lam

Received: 14 October 2014 Accepted: 21 March 2015

Published online: 29 April 2015

References

Abbasi-Shavazi MJ, McDonald P, Hosseini-Chavoshi M (2009) The fertility transition in Iran. Revolution and Reproduction. Springer, Dordrecht

Aghajanian A (1995) A new direction in population policy and family planning in the Islamic Republic of Iran. Asia-Pacific Popul J United Nations 10(1):3-20

Agüero JM, Marks MS (2008) Motherhood and female labor force participation: evidence from infertility shocks. The American Economic Review, pp 500-504

Almond D, Edlund L (2008) Son-biased sex ratios in the 2000 United States Census. Proc Natl Acad Sci 105(15):5681-5682

Angrist JD, Evans WN (1998) Children and their parents' labor supply: evidence from exogenous variation in family size. Am Econ Rev 88(3):450-477

Becker GS, Lewis HG (1974) Interaction between quantity and quality of children. In Economics of the family: Marriage, children, and human capital. UMI, pp 81-90

Ben-Porath Y, Welch F (1976) Do sex preferences really matter? The Quarterly Journal of Economics, pp 285-307

Bronars SG, Grogger J (1994) The economic consequences of unwed motherhood: using twin births as a natural experiment. Am Econ Rev 84(5):1141-1156

Chun H, Oh J (2002) An instrumental variable estimate of the effect of fertility on the labour force participation of married women. Applied Economics Letters 9(10):631-634

Goldin C (1995) Career and family: College women look to the past (No. w5188). National Bureau of Economic Research

Hoodfar H (1996) Bargaining with fundamentalism: women and the politics of population control in Iran. Reprod Health Matters 4(8):30-40

Majbouri M (2010) Against the wind: labor force participation of women and economic instability in Iran. Available at SSRN 2419323

Majbouri M (2015) Oil, patriarchy, and female labor force participation, Working paper

Mehryar AH, Ahmad-Nia S, Kazemipour S (2007) Reproductive health in Iran: pragmatic achievements, unmet needs, and ethical challenges in a theocratic system. Stud Fam Plann 38(4):352-361

Rosenzweig MR, Wolpin KI (1980) Testing the quantity-quality fertility model: the use of twins as a natural experiment. Econometrica J Econ Soc 48(1):227-240

Ross ML (2008) Oil, Islam, and women. American Political Science Review 102(01):107-123

Schultz TP (1981) Economics of population. Perspectives on Economics Series

Sharabi H (1988) Neopatriarchy: a theory of distorted change in arab society. Oxford University Press, New York

Stock JH, Yogo M (2005) Testing for weak instruments in linear IV regression. Identification and inference for econometric models: Essays in honor of Thomas Rothenberg

\section{Submit your manuscript to a SpringerOpen ${ }^{\circ}$ journal and benefit from:}

- Convenient online submission

Rigorous peer review

- Immediate publication on acceptance

- Open access: articles freely available online

- High visibility within the field

Retaining the copyright to your article

Submit your next manuscript at $\boldsymbol{~ s p r i n g e r o p e n . c o m ~}$ 